Available online on 15.11 .2016 at http://jddtonline.info
Open access to Pharmaceutical and Medical research
(C) 2016, publisher and licensee JDDT, This is an Open Access article which permits unrestricted
noncommercial use, provided the original work is properly cited

\title{
Prevalence of potentially inappropriate medications in ayder REFERRAL HOSPITAL, TIGRAY REGION, NORTHERN ETHIOPIA: PROSPECTIVE STUDY
}

\author{
Fantaye Teka ${ }^{1}$, Gebrehiwot Teklay ${ }^{2}$, Eskinder Ayalew ${ }^{2}$, Terefe Teshome Kassa $^{2 *}$, \\ ${ }^{1}$ Forecasting and Capacity Building Directorate, The Federal Democratic Republic of Ethiopia Pharmaceutical Fund and Supply Agency, \\ Addis Ababa, Ethiopia \\ ${ }^{2}$ Department of Pharmacy, College of Health Sciences, Mekelle University, Mekelle, Ethiopia
}

\section{ABSTRACT}

Background: Potentially inappropriate medication (PIM) use includes the use of drugs with higher risk where adverse drug effect outweighs the clinical benefit, especially when more effective alternative therapy is available.

Objective: The aim of this study was to assess prevalence and risk factors associated with the use of PIMs in elderly patients at medical ward of Ayder Referral Hospital (ARH), Tigray region, Northern Ethiopia.

Methods: A facility based prospective cross sectional study was conducted among 140 elderly patients from February 6, 2014 to May 05, 2014 in ARH. Patients with age $\geq 60$ years admitted to medical ward during the study period were randomly selected. Data were collected with a structured questionnaire and analyzed using statistical package for social science (SPSS, IBM Corporation) version 20. Binary logistic regression was used to analyze factors associated with occurrence of PIM.

Results: Of 140 patients, $52.1 \%$ were males and forty $(28.6 \%)$ of patients received at least one potentially inappropriate medication. The most commonly used potential inappropriate medications were metoclopramide (25.58\%), nifedipine (16.28\%), diazepam $(13.95 \%)$ and meperedine $(13.95 \%)$. Above half of $(58 \%)$ patients encountered polypharmacy. Thirty eight percent of the participants' had comorbid conditions. In the binary logistic analysis, patients with polypharmacy were more likely to receive PIMs [AOR 4.163: $95 \%$ CI 1.75- 9.92, p=0.001].

Conclusions: Prevalence of PIMs in elderly patients admitted to ARH was high. Polypharmacy was identified as the independent predicator of the uses of PIMs. Clinical pharmacists' are in a position to alert and monitor the exposure to PIMs as part of multidisciplinary team.

Keywords: Elderly, Potential inappropriate medication, Beer's criteria, Ethiopia

\footnotetext{
*Corresponding author

Terefe Teshome Kassa; Department of Pharmacy, College of Health Sciences, Mekelle University, Mekelle, Ethiopia; Tel. +251912449098; Email: terefe1991@gmail.com; P.O.Box:1871; Mekelle, Ethiopia
}

Article Info

Received 21 March 2016; Review Completed 07 July 2016; Accepted 21 Oct 2016, Available online 15 Nov 2016

Cite this article as: Teka F, Teklay G, Ayalew E, Kassa TT, Prevalence of potentially inappropriate medications in ayder referral hospital, tigray region, northern Ethiopia: prospective study, Journal of Drug Delivery \& Therapeutics. 2016; 6(6):16-21

DOI: http://dx.doi.org/10.22270/jddt.v6i6.1238 $\quad$ URI: http://jddtonline.info/index.php/jddt/article/view/1238

Authors' contributions: FT, GT, TT have contributed during the study designing, data collection and data analysis. FT, GT, EA and TT were involved in the interpretation of finding and development of the manuscript.

Authors' information: FT is Forecasting and Capacity Building officer in the Federal Democratic Republic of Ethiopia Pharmaceutical Fund and Supply Agency, Addis Ababa, Ethiopia; GT is assistant professor and clinical pharmacist in Mekelle University College of Health Sciences; EA is a lecturer and clinical pharmacist in Mekelle University College of Health Sciences; TT is assistant lecturer of pharmacoepidemiology and social pharmacy in Mekelle University College of Health Sciences. 


\section{INTRODUCTION}

Ageing is a biological process broadly beyond human control and often has its own dynamic. Increasing age usually associated with changes in body composition and physiology, may result in the change of pharmacokinetics and pharmacodynamics of administered drugs ${ }^{1,2}$. The adulthood of 60 or 65 , almost correlative to retirement ages in most western nations is said to be the starting of old age ${ }^{3}$. Alongside age-related steady changes, the rates for perpetual infections and comorbidity increments are trailed by constant medication treatment. On the other hand, drug treatment in the elders is substantially more difficult and complex than in younger adults, particularly because of the comorbidity and the expanding number of medications for the treatment of diverse conditions ${ }^{1,4,5}$

Preventable medication related problems are common and costly in elders and may lead to poor outcomes. PIM use includes the use of drugs with higher risk where adverse drug effect outweighs the clinical benefit, especially when more effective alternative therapy is available ${ }^{5,6}$. PIMs have been reported as an important cause of iatrogenic morbidity, mortality and increased healthcare costs ${ }^{7,8}$. General medication related problems among patients with at least one PIM prescription were significantly higher than non PIM group with $14.3 \%$ and $4.7 \%$ respectively ${ }^{8}$. As per Hedna et al., PIMs were considered as the cause of $60 \%$ of adverse drug reactions (ADRs) influencing vascular, half of ADRs affecting the nervous system and $62.5 \%$ of ADRs bringing about falls ${ }^{9}$. However, the use of PIM is common; different studies showed with range between 34.5- $82.6 \%$ of ageing patients were received at least one medication with risk outweighs the benefit ${ }^{10-12}$.

Avoiding the use of inappropriate and high-risk drugs may be an important, simple, and effective strategy in reducing medication-related problems and adverse drug events in older adults. Beer and colleagues developed and published explicit list of PIMs for nursing home residents in 1991 subsequently expanded and revised in 1997, 2003 then 2012 to include all settings of geriatric care ${ }^{6,13-15}$ which is important for recognizing and avoiding medication with higher risks in seniors to improve quality care. However, studies with respect to the use of PIMs in Ethiopia are uncommon.

Therefore, the main aim of this study was to identify the prevalence and most commonly used PIMs which will be used as a base line data for health service providers for promoting rational use of drugs. Furthermore, the purpose inlcudes identifying risk factors associated with PIMs in elderly patients at medical ward of ARH, Tigray region, Northern Ethiopia. Understanding risk factors make intervention easy for care givers to targeting factors to improve quality of patients care in older adults.

\section{METHODS AND MATERIALS}

\section{Study area and Period}

The study was conducted from February 6, 2014 to May 05, 2014 in ARH located in Mekelle, capital city of Tigray Region, Northern Ethiopia. ARH is a teaching
Hospital of Mekelle University and the largest Referral Hospital in Tigray Regional State which is located $783 \mathrm{~km}$ North of Addis Ababa, capital of Ethiopia. ARH commenced rendering its referral and non-referral services to the 8 million populations in areas of the Tigray, Afar and Southeastern parts of the Amhara Regional States. It provides a broad range of medical services to both in and out patients of all age groups.

\section{Study Design and Study Population}

A facility based prospective cross sectional study was conducted. To be eligible to participate in the study, older adults were required age greater than or equal to 60 years, admitted to the medical ward, competent to give informed consent, at least talking one medication and not critically ill.

\section{Sample size determination}

The sample size required for the study was determined using the formula for estimation of single proportion, based on the PIMs proportions of $27 \%{ }^{16}, 5 \%$ margin of error at 95\% confidence level. Total of 322 elderly patients were admitted to ARH during the study period and finally adjusting for finite population correction a sample of 157 patients was taken. Study participants were selected employing simple random sampling techniques. List of admitted elderly patient at a particular time was considered as sampling frame. Sampling interval was obtained by dividing the number of elderly patients admitted during the study period divided by the sample size which gives 2 . The first patient was selected randomly and every other patient was included in the study.

\section{Data collection methods and tools}

Data were collected using a structured questionnaire and the questionnaire included two parts. The first part contained questions about the socio-demographic characteristics of the patients and diagnosis. The second part contained questions related to drug regimens prescribed including name, dosages, frequency and duration of administration. The questionnaire was pretested in $10 \%$ of sample size in out of study area in Mekelle General Hospital. It was developed in English language then translated into local language and data were collected by trained graduating class pharmacy students.

\section{Operational definitions}

PIMs refers to any medication listed in updated 2012 Beers criteria to be avoided in elderly patients ${ }^{15}$.

Polypharmacy refers as the use of multiple medications generally referred to five or more prescribed drugs at a time ${ }^{17}$.

2012 Updated Beer's Criteria refers to explicit list of medications prepared by American Geriatric Society to be avoided in older adults in 2012 because risk outweighs benefits ${ }^{15}$. 


\section{Data analysis and management}

First of all, questionnaires were checked for data completeness. After that, code was given to each questionnaire then data were entered to statistical package for social science (SPSS, IBM Corporation) version 20 for analysis. Finally, the descriptive statistics (frequency, percentage, mean, standard deviation) were used to examine the normality of the data and describe the analysis. Furthermore, logistic regression with $95 \%$ confidence interval was done to determine risk factors associated with PIMs and P value of less than 0.05 was considered statistically significant.

\section{Ethical clearance}

Ethical clearance was obtained from the Institutional Ethics Review Board of the College of Health Sciences, Mekelle University(ERC 0362/2014). Study participants briefed about the objective of the study with the local language (Tigrigna) version and informed consent were obtained. The confidentiality and right to refuse participation of the study participants were maintained.

\section{RESULTS}

Total of 157 elderly patients approached 140 patients were agreed to participate in the study with response rate of $89.2 \%$. The mean age was $68.39 \pm 7.26$ years and male patients represented $52.1 \%$ of the study population. Patients stayed in the hospital with a mean of $12.51 \pm$ 8.99 days while nearly one third $(32.9 \%)$ of the participants had two comorbidities. The sum of the number of medication at a time per patient was 814 drugs, giving an average of $5.81 \pm 3.94$. Fifty-nine (40\%) patients had less than five drugs whereas twenty-five (17.9\%) patients had nine drugs or more prescribed for them (Table 1).

Table 1: Demographic and clinical characterestics of study participants in internal medicine ARH, Tigray region, Northern Ethiopia( $\mathrm{N}=140)$

\begin{tabular}{|l|l|l|}
\hline Characterestics & Frequence $(\mathbf{N})$ & Percentage $(\%)$ \\
\hline Gender & \multicolumn{2}{l|}{} \\
\hline Male & 73 & 52.1 \\
\hline Female & 67 & 47.9 \\
\hline Age (mean \pm SD) & $68.39 \pm 7.26$ & \\
\hline $60-69$ & 76 & 54.3 \\
\hline $70-79$ & 48 & 34.3 \\
\hline$\geq 80$ & 16 & 11.4 \\
\hline Hospital stay in days (mean \pm SD) & $12.51 \pm 8.99$ & 52.1 \\
\hline $1-10$ & 73 & 31.4 \\
\hline $11-20$ & 44 & 16.4 \\
\hline$\geq 21$ & 23 & \\
\hline Prescribed drugs per patient (mean \pm SD) & $5.81 \pm 2.98$ & 42.1 \\
\hline$<5$ & 59 & 40.0 \\
\hline $5-8$ & 56 & 17.9 \\
\hline$\geq 9$ & 25 & \\
\hline
\end{tabular}

In this study, Eighty six $(61.4 \%)$ patients had at least one cardiovascular disease (CVD) or renal disease. Heart failure was the common CVD accounting for 22.8 $\%$, followed by hypertension $20 \%$ and $6.4 \%$ had both. Whereas infectious disease was proved in $58.6 \%$ patients, Pneumonia accounted for $32 \%$, followed by Tuberculosis $(15 \%)$, urinary tract infection $(5.7 \%)$ and others. The third-ranked class hematological disorder diagnosed in $25 \%$ of participants, of them anemia diagnosed in $13.6 \%$, pancytopenia in 5\% and deep venous thrombosis in $3.6 \%$. Moreover, endocrine disorder prevalence was $15 \%$ with commonest of diabetic mellitus observed in $13.6 \%$ of study participants.

Reviewing of the prescribed medications using the 2012 Updated Beer's Criteria indicated that 40 patients received at least one PIM, giving a prevalence rate of
$28.6 \%$. Forty three PIMs were prescribed to 40 patients during this study period. Furthermore, three of patients each got 2 PIMs during their stay. The most commonly prescribed drug was metoclopramide identified PIMs in $11(25.58 \%$ of all PIM) cases followed by nifedipine seven $(16.28 \%)$ cases while diazepam and meperidine were implicated in six (14\%) cases each (Table 2).

Binary logistic regression analysis was performed to determine risk factors associated with PIMs. Polypharmacy was significantly associated with PIMs i.e. patients on polypharmacy were four times more likely to have PIMs [AOR, 4.163: 95\% CI 1.75 - 9.92 $\mathrm{p}=0.001]$ compared to patients who took less than five medications per day. However, age, sex and comorbidity had no significant association with prescribing of PIMs (Table 3). 
Table 2: Prescribed drugs in elderlies that should be avoided based on Beer's criteria in ARH, Northern Ethiopia, 2015

\begin{tabular}{|c|c|c|c|}
\hline Drug name & Frequency & Percent $(\mathbf{n} / \mathbf{T})$ & Potential risk* \\
\hline Metoclopramide & 11 & 25.58 & $\begin{array}{l}\text { Can cause extrapyramidal effects including tardive } \\
\text { dyskinesia; risk may be even greater in frail older adult. }\end{array}$ \\
\hline $\begin{array}{l}\text { Nifedipine } \\
\text { (immediate release) }\end{array}$ & 7 & 16.28 & $\begin{array}{l}\text { Potential for hypotension; risk of precipitating myocardial } \\
\text { ischemia. }\end{array}$ \\
\hline Diazepam & 6 & 13.95 & $\begin{array}{l}\text { Older adults have increased sensitivity to benzodiazepines } \\
\text { and slower metabolism of long-acting agents. Increase risk } \\
\text { of cognitive impairment, delirium, falls, fractures, and } \\
\text { motor vehicle accidents in older adults }\end{array}$ \\
\hline Meperedine & 6 & 2 & $\begin{array}{l}\text { Not an effective oral analgesic in dosages commonly used; } \\
\text { may cause neurotoxicity. }\end{array}$ \\
\hline $\begin{array}{l}\text { Spironolactone }>25 \\
\mathrm{mg} / \mathrm{d} \text { for } \mathrm{CHF} \text {, with } \\
\mathrm{KCl} \text { and } \mathrm{ACEI}\end{array}$ & 5 & 11.63 & The risk of hyperkalemia is higher in older adults \\
\hline Sliding scale insulin & 3 & 6.98 & $\begin{array}{l}\text { Higher risk of hypoglycemia without improvement in } \\
\text { hyperglycemia management regardless of care setting }\end{array}$ \\
\hline Indomethacin & 2 & 4.65 & Increases risk of GI bleeding and PUD in high-risk groups. \\
\hline Amitriptyline & 2 & 4.65 & $\begin{array}{l}\text { Highly anticholinergic, sedating, and cause orthostatic } \\
\text { hypotension }\end{array}$ \\
\hline Digoxin $>0.125 \mathrm{mg} / \mathrm{d}$ & 1 & 2.32 & $\begin{array}{l}\text { no additional benefit and may increase risk of toxicity; } \\
\text { slow renal clearance may lead to risk of toxic effects }\end{array}$ \\
\hline Total & 43 & 100 & 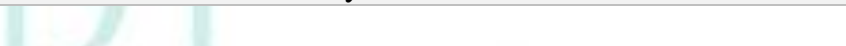 \\
\hline
\end{tabular}

Table 3: Factors associated with potentially inappropriate prescribing in ARH, northern Ethiopia, 2015

\begin{tabular}{|c|c|c|c|c|c|c|c|}
\hline \multirow[t]{2}{*}{ Variable } & \multirow[t]{2}{*}{ Category } & \multicolumn{2}{|l|}{ PIM } & \multirow{2}{*}{$\begin{array}{l}\text { Significance } \\
\text { (p value) }\end{array}$} & \multirow[t]{2}{*}{ Adjust Odds ratio } & \multicolumn{2}{|c|}{$95 \%$ CI for EXP } \\
\hline & & No $(n)$ & Yes (n) & & & Lower & Upper \\
\hline \multirow[t]{3}{*}{ Age } & $60-69$ & 52 & 24 & & & & \\
\hline & $70-79$ & 38 & 10 & 0.231 & 0.577 & 0.235 & 1.419 \\
\hline & $\geq 80$ & 10 & 6 & 0.455 & 1.588 & 0.472 & 5.345 \\
\hline \multirow[t]{2}{*}{ Sex } & Male & 50 & 23 & & & & \\
\hline & Female & 50 & 17 & 0.609 & 0.812 & 0.367 & 1.800 \\
\hline \multirow[t]{2}{*}{ Comorbidity } & No & 19 & 6 & & & & \\
\hline & Yes & 81 & 43 & 0.613 & 0.732 & 0.218 & 2.457 \\
\hline \multirow[t]{2}{*}{ Polypharmacy } & $<5$ drugs & 51 & 8 & & & & \\
\hline & $\geq 5$ drugs & 49 & 32 & 0.001 & 4.163 & 1.747 & 9.92 \\
\hline
\end{tabular}

\section{DISCUSSION}

The aim of this study was to estimate prevalence of PIM in elderly patients in the ARH which is one of the tertiary care settings in the country. We found that more than one fourth $(28.6 \%)$ of the study participants had encountered at least one PIM during their hospital stay. A systematic review showed that the prevalence of PIM using Beer's criteria range from $11.5 \%$ to $62.5 \% 18$ where our finding was within this range. Furthermore, the result of present study was almost similar to the previously conducted study on 1252 patients in North Western Ethiopia with a prevalence of $27.7 \%$ of PIM ${ }^{16}$. Moreover, this finding was comparable with studies done on older patients admitted to six European hospitals with overall PIMs prevalence of $30.4 \%$ using 2012 Updated Beer's Criteria, varying from $22.7 \%$ in Prague to $43.3 \%$ in Geneva ${ }^{11}$. In contrary, some studies revealed higher prevalence rate of $49 \%, 53.6 \%$, and $62.4 \%$ of PIM in USA ${ }^{19}$, France ${ }^{20}$ and Croatia ${ }^{10}$ respectively. The difference in the prevalence of PIMs reported in various studies may be due to the differences in patient and disease characteristics, prescribing patterns, number attending physician and screening criteria $^{18-24}$.

The average number of drugs prescribed per patient in this study (5.81) was higher than results from other general prescription studies done in Nigeria (3.8) ${ }^{25}$, Turkey (2.9) ${ }^{26}$, India (4.3) ${ }^{27}$ and Brazil (4.4) ${ }^{28}$. In contrary, this finding was lower than studies carried out among geriatric patients in USA an average of 8.1 drugs per prescription ${ }^{29}$. This significant difference in the number of prescribed drugs for patients in our study when compared to developing countries (e.g., Nigeria) is the matter of outpatient set up, where participants involved. To the opposite developed countries (e.g. USA) could be attributed a functional health insurance policy for the elderly which may give more access to medications. A study done in Indonesia revealed that 24 $\%$ of geriatric institutionalized patients received more than five drugs per day during the hospital stay, which has exaggerated gap to our study $(47.14 \%)^{30}$. This is partly due to infectious comorbidity observed besides aging related deterioration. 
Our finding indicated that more than half of the study participants $81(57.9 \%)$ used five or more medications at times, which is an important factor that was associated $[\mathrm{AOR}=4.16,95 \% \mathrm{CI}: 1.75,9.92]$ with a stronger probability to exposure of PIMs. According to Weng et al., there were strong associations between higher PIMs with increasing number of medications ${ }^{31}$. Furthermore, a study done in China showed that an increased number of drugs used was identified as an independent factor associated with PIM ${ }^{32}$. In contrary to this study finding some studies showed additional factors associated with PIM such as age, sex and hospitalization ${ }^{20,33-36}$. A metaanalysis done on determinant factors for the use of PIM for the elderly pointed out, there were high degree of heterogeneity among the studies and only polypharmacy presented a positive association ${ }^{37}$. This difference among studies may be due to selection, stratification of the sample and criteria for determining of PIM.

Four commonly reported inappropriate medications which accounts more than two third $(69.76 \%)$ of all encounters where metoclopramide, Nifedipine, diazepam and meperidine. Our finding was comparable with previous studies done in Ethiopia ${ }^{16,38}$. According to Jhaveri et al., the most common inappropriate medications were metoclopramide, alprazolam, diazepam, digoxin, and diclofenac ${ }^{39}$. Moreover, some studies showed that almost same group of drugs especially benzodiazepines, NSAIDs and antihistamines associated with PIM 26,40,41. In this study, metoclopramide was the most commonly prescribed and accounts $25.58 \%$ of all PIM which is relatively higher. This high rate of prescription may be due to lack of up dated knowledge among physicians regarding

\section{REFERENCES:}

1. Stegemann S, Ecker F, Maio M, et al. Geriatric drug therapy: Neglecting the inevitable majority. Ageing research reviews. 2010;9(4):384-398.

2. Gillespie U. Effects of Clinical Pharmacists' Interventions: on Drug-Related Hospitalisation and Appropriateness of Prescribing in Elderly Patients. 2012.

3. Organization WH. Proposed Working Definition of an Older Person in Africa for the MDS Project: Definition of an older or elderly person 2013 .

4. Hamilton HJ, Gallagher PF, O'Mahony D. Inappropriate prescribing and adverse drug events in older people. $B M C$ geriatrics. 2009;9(1):5.

5. Spinewine A, Schmader KE, Barber N, et al. Appropriate prescribing in elderly people: how well can it be measured and optimised? The Lancet. 2007;370(9582):173-184.

6. Beers MH, Ouslander JG, Rollingher I, Reuben DB, Brooks J, Beck JC. Explicit criteria for determining inappropriate medication use in nursing home residents. Archives of internal medicine. 1991;151(9):1825-1832.

7. Rodrigues AB, Takahashi JA, Secoli S, Nobre MC, Mónica M, GarridoJulio F. Mortality Associated with the Use of Inappropriate Drugs According Beers Criteria: a Systematic Review. Advances in Pharmacology and Pharmacy. 2013;1(2):74-84.

8. Fick DM, Mion LC, Beers MH, L Waller J. Health outcomes associated with potentially inappropriate medication use in older adults. Research in nursing \& health. 2008;31(1):42-51. metoclopramide inclusion in new 2012 Updated Beer's Criteria. Its use is largely considered inappropriate because of the possibility of extrapyramidal adverse reactions ${ }^{12}$.

The limitation of this study is cross-sectional outline does not permit building up the transience of the connection factors. It also does not connect adverse reaction reactions outcome due to PIMs use. However, one of the strength this study provided was information about the most common PIMs. In contrast to previously study done in Ethiopia it identifies the factors associated with PIMs which helps to overcome the problem.

\section{CONCLUSION}

In conclusion, nearly one third elderly patients were exposed to PIMs during the study period and metoclopramide was the most commonly prescribed medications. Polypharmacy was identified as the independent predicator of the uses of PIMs. Clinical pharmacists' are in a position to alert and monitor the exposure to PIMs as part of multidisciplinary team.

\section{ACKNOWLEDGMENTS}

The authors acknowledge the elderly patients for their participation as well as the hospital management for their unreserved contribution in the data collection process.

\section{Conflict of Interest}

The authors declared that there is no conflict of interests. We received no funding for the study.

9. Hedna K, Hakkarainen KM, Gyllensten H, Jönsson AK, Petzold M, Hägg S. Potentially inappropriate prescribing and adverse drug reactions in the elderly: a population-based study. European journal of clinical pharmacology. 2015;71(12):1525-1533.

10. Popovic B, Quadranti NR, Matanovic SM, et al. Potentially inappropriate prescribing in elderly outpatients in Croatia. European journal of clinical pharmacology. Jun 2014;70(6):737-744.

11. Gallagher P, Lang PO, Cherubini A, et al. Prevalence of potentially inappropriate prescribing in an acutely ill population of older patients admitted to six European hospitals. European journal of clinical pharmacology. 2011;67(11):1175-1188.

12. de Lima TJV, Garbin CAS, Garbin AJÍ, Sumida DH, Saliba O. Potentially inappropriate medications used by the elderly: prevalence and risk factors in Brazilian care homes. $B M C$ geriatrics. 2013;13(1):52.

13. Beers MH. Explicit criteria for determining potentially inappropriate medication use by the elderly: an update. Archives of internal medicine. 1997;157(14):1531-1536.

14. Fick DM, Cooper JW, Wade WE, Waller JL, Maclean JR, Beers MH. Updating the Beers criteria for potentially inappropriate medication use in older adults: results of a US consensus panel of experts. Archives of internal medicine. 2003;163(22):2716-2724. 
15. Campanelli CM. American Geriatrics Society updated beers criteria for potentially inappropriate medication use in older adults: the American Geriatrics Society 2012 Beers Criteria Update Expert Panel. Journal of the American Geriatrics Society. 2012;60(4):616

16. Mekonnen BA, Bhagavathula SA. Inappropriate medication use in the elderly population attending gondar University hospital: a preliminary assessment. Int J Pharm Pharm Sci. 2014;6(10):540-543.

17. Dagli RJ, Sharma A. Polypharmacy: a global risk factor for elderly people. Journal of international oral health: $\mathrm{JIOH}$. 2014;6(6):i.

18. Bongue $\mathrm{B}$, Laroche $\mathrm{ML}$, Gutton $\mathrm{S}$, et al. Potentially inappropriate drug prescription in the elderly in France: a population-based study from the French National Insurance Healthcare system. European journal of clinical pharmacology. Dec 2011;67(12):1291-1299.

19. Rothberg MB, Pekow PS, Liu F, et al. Potentially inappropriate medication use in hospitalized elders. Journal of hospital medicine. 2008;3(2):91-102.

20. Morin L, Fastbom J, Laroche ML, Johnell K. Potentially inappropriate drug use in older people: a nationwide comparison of different explicit criteria for population-based estimates. British journal of clinical pharmacology. Aug 2015;80(2):315-324.

21. Frankenthal D, Lerman Y. The impact of hospitalization on potentially inappropriate prescribing in an acute medical geriatric division. International journal of clinical pharmacy. Feb 2015;37(1):60-67.

22. Lund BC, Steinman MA, Chrischilles EA, Kaboli PJ. Beers Criteria as a proxy for inappropriate prescribing of other medications among older adults. Annals of Pharmacotherapy. 2011;45(11):1363-1370.

23. Holmes HM, Luo R, Kuo YF, Baillargeon J, Goodwin JS Association of potentially inappropriate medication use with patient and prescriber characteristics in Medicare Part D. Pharmacoepidemiology and drug safety. 2013;22(7):728-734.

24. Moriarty F, Bennett K, Fahey T, Kenny RA, Cahir C. Longitudinal prevalence of potentially inappropriate medicines and potential prescribing omissions in a cohort of community-dwelling older people. European journal of clinical pharmacology. 2015;71(4):473-482.

25. Fadare JO, Agboola SM, Opeke OA, Alabi RA. Prescription pattern and prevalence of potentially inappropriate medications among elderly patients in a Nigerian rural tertiary hospital. Therapeutics and clinical risk management. 2013;6:115-120.

26. Ay P, Akici A, Harmanc H. Drug utilization and potentially inappropriate drug use in elderly residents of a community in Istanbul, Turkey. International journal of clinical pharmacology and therapeutics. Apr 2005;43(4):195-202.

27. Zaveri HG, Mansuri SM, Patel VJ. Use of potentially inappropriate medicines in elderly: A prospective study in medicine out-patient department of a tertiary care teaching hospital. Indian journal of pharmacology. Apr 2010;42(2):9598.

28. Teixeira JJV, Crozatti MTL, dos Santos CA, Romano-Lieber NS. Potential drug-drug interactions in prescriptions to patients over 45 years of age in primary care, southern Brazil. 2012

29. Steinman MA, Seth Landefeld C, Rosenthal GE, Berthenthal D, Sen S, Kaboli PJ. Polypharmacy and prescribing quality in older people. Journal of the American Geriatrics Society. 2006;54(10):1516-1523.

30. Rahmawati F, Pramantara I, Rohmah W, Sulaiman S. Polypharmacy and unnecessary drug therapy on geriatric hospitalized patients in yogyakarta hospitals, Indonesia. Int $J$ Pharm Pharm Sci. 2009;1(1):6-11.

31. Weng MC, Tsai CF, Sheu KL, et al. The impact of number of drugs prescribed on the risk of potentially inappropriate medication among outpatient older adults with chronic diseases. QJM : monthly journal of the Association of Physicians. Nov 2013;106(11):1009-1015.

32. Lao CK, Chan KK, Tou CF, Tong HHY, Chan A. Potentially inappropriate prescribing and drug-drug interactions among elderly Chinese nursing home residents in Macao. International journal of clinical pharmacy. 2013;35(5):805812.

33. Guaraldo L, Cano FG, Damasceno GS, Rozenfeld S. Inappropriate medication use among the elderly: a systematic review of administrative databases. BMC geriatrics. 2011;11(1):79.

34. Eiras A, Teixeira MA, Gonzalez-Montalvo JI, Castell MV, Queipo R, Otero A. [Consumption of drugs in over 65 in Porto (Portugal) and risk of potentially inappropriate medication prescribing]. Atencion primaria / Sociedad Espanola de Medicina de Familia y Comunitaria. May 232015.

35. Frankenthal D, Lerman Y, Kalendaryev E. Potentially inappropriate prescribing among older residents in a geriatric hospital in Israel. International journal of clinical pharmacy. Oct 2013;35(5):677-682

36. de Oliveira MA, Francisco PM, Costa KS, Barros MB. [Selfmedication in the elderly population of Campinas, Sao Paulo State, Brazil: prevalence and associated factors]. Cadernos de saude publica. Feb 2012;28(2):335-345.

37. Santos TR, Lima DM, Nakatani AY, Pereira LV, Leal GS, Amaral RG. Medicine use by the elderly in Goiania, Midwestern Brazil. Revista de saude publica. Feb 2013;47(1):94-103.

38. Teni FS, Gedif T. Prevalence and Predictors of Inappropriate Medications Prescribing Among Elderly Outpatients at a University Hospital in Northwestern Ethiopia: A Retrospective Cross-Sectional Study. Ethiopian Pharmaceutical Journal. 2015;30(2):124-132.

39. Jhaveri BN, Patel TK, Barvaliya MJ, Tripathi C. Utilization of potentially inappropriate medications in elderly patients in a tertiary care teaching hospital in India. Perspectives in Clinical Research. 2014;5(4):184.

40. Vezmar Kovacevic S, Simisic M, Stojkov Rudinski S, et al. Potentially inappropriate prescribing in older primary care patients. PloS one. 2014;9(4):e95536.

41. Oliveira MG, Amorim WW, de Jesus SR, Rodrigues VA, Passos LC. Factors associated with potentially inappropriate medication use by the elderly in the Brazilian primary care setting. International journal of clinical pharmacy. Aug 2012;34(4):626-632. 